\title{
Protecting Wild Dolphins and Whales: Current Crises, Strategies, and Future Projections
}

\author{
Lori Marino, ${ }^{1}$ Frances Gulland, ${ }^{2}$ and E. C. M. Parsons ${ }^{3}$ \\ ${ }^{1}$ Neuroscience and Behavioral Biology and Center for Ethics, Emory University and The Kimmela Center for Animal Advocacy, \\ Atlanta, GA 30322, USA \\ ${ }^{2}$ The Marine Mammal Center, Sausalito, CA 95965-2619, USA \\ ${ }^{3}$ Environmental Science \& Policy, George Mason University, Fairfax, VA 203-4444, USA \\ Correspondence should be addressed to Lori Marino, lmarino@emory.edu \\ Received 4 August 2012; Accepted 4 August 2012 \\ Copyright (C) 2012 Lori Marino et al. This is an open access article distributed under the Creative Commons Attribution License, \\ which permits unrestricted use, distribution, and reproduction in any medium, provided the original work is properly cited.
}

In the past few years, we witnessed the first anthropogeniccaused extinction of a dolphin species in our lifetimes: the Baiji (Lipotes vexillifer). There are currently several other cetacean species on the brink of extinction or endangered. Moreover, many cetacean subpopulations are under siege from various stressors. This year alone, we have witnessed a number of unusual high mortality events in the Gulf of Mexico, and off the coasts of Peru and New England. As all of these stressors, that is, climate change, chemical, pathogen and noise pollution, ship traffic, and fisheries bycatch increase, we are likely to see more of these tragic events in the near future. At a time when the problems cetaceans face are converging with a myriad of other issues, the possible approaches to be employed to mitigate these problems require unprecedented flexibility and sophistication.

Adding to the complexity of these issues is the knowledge that cetaceans are not only intelligent, highly social, and self-aware mammals [1], but they possess cultural traditions [2]. These characteristics necessitate a move from the traditional "numbers-based" approach of conservation to a more progressive protection-based strategy that takes into account cumulative impacts of multiple stressors on their health, their psychology as unique individuals, their social complexity, and their cultural identities. No longer will traditional population studies provide the totality of the picture for wild cetaceans. The approach towards this group of mammals must be expanded to accommodate our new view of them as socially complex and cultural individuals who are each an important component of their group, and arguably, ecosystem. Sustainability is not the only criterion for making conservation decisions. Now health and animal welfare must be considered if we are to accept the current scientific understanding of who cetaceans are.

In this special issue, we will explore the topic of protecting wild dolphins and whales from several angles. The papers in this volume reach across previously separated domains and also reflect the new approach of moving beyond the numbers and incorporating individual welfare into conservation analyses. New stressors and threats of concern are highlighted, such as marine debris and the growth of whale watching. Whale watching is currently the most globally important economic activity involving cetaceans that have been put forward by many as a sustainable practice, that is, obviously more ethically acceptable than whaling. But even so, without proper management, even this activity can be a stressor to cetacean populations. The papers also reflect the urgency that is felt as we strive to protect and conserve wild cetaceans. We hope that the papers in this volume engender further thinking about new and even further "out of the box" ideas about how to ensure that wild cetaceans move into the future in their own natural habitats.

\section{Lori Marino Frances Gulland E. C. M. Parsons}

\section{References}

[1] D. Reiss and L. Marino, "Mirror self-recognition in the bottlenose dolphin: a case of cognitive convergence," Proceedings of 
the National Academy of Sciences of the United States of America, vol. 98, no. 10, pp. 5937-5942, 2001.

[2] H. Whitehead, "The cultures of whales and dolphins," in Whales and Dolphins: Cognition, Culture, Conservation and Human Perceptions, P. Brakes and M. P. Simmonds, Eds., Earthscan, London, UK, 2011. 

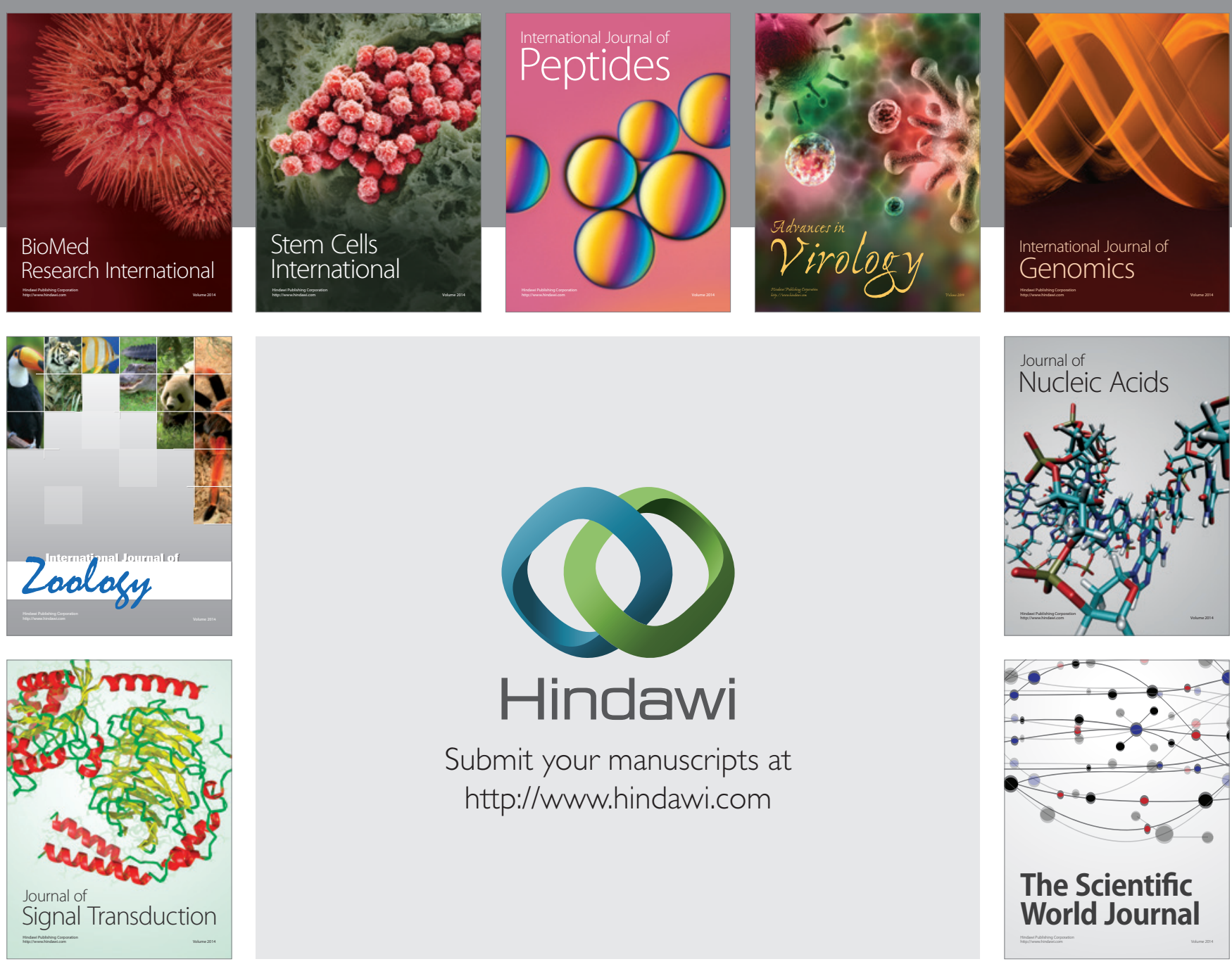

Submit your manuscripts at

http://www.hindawi.com
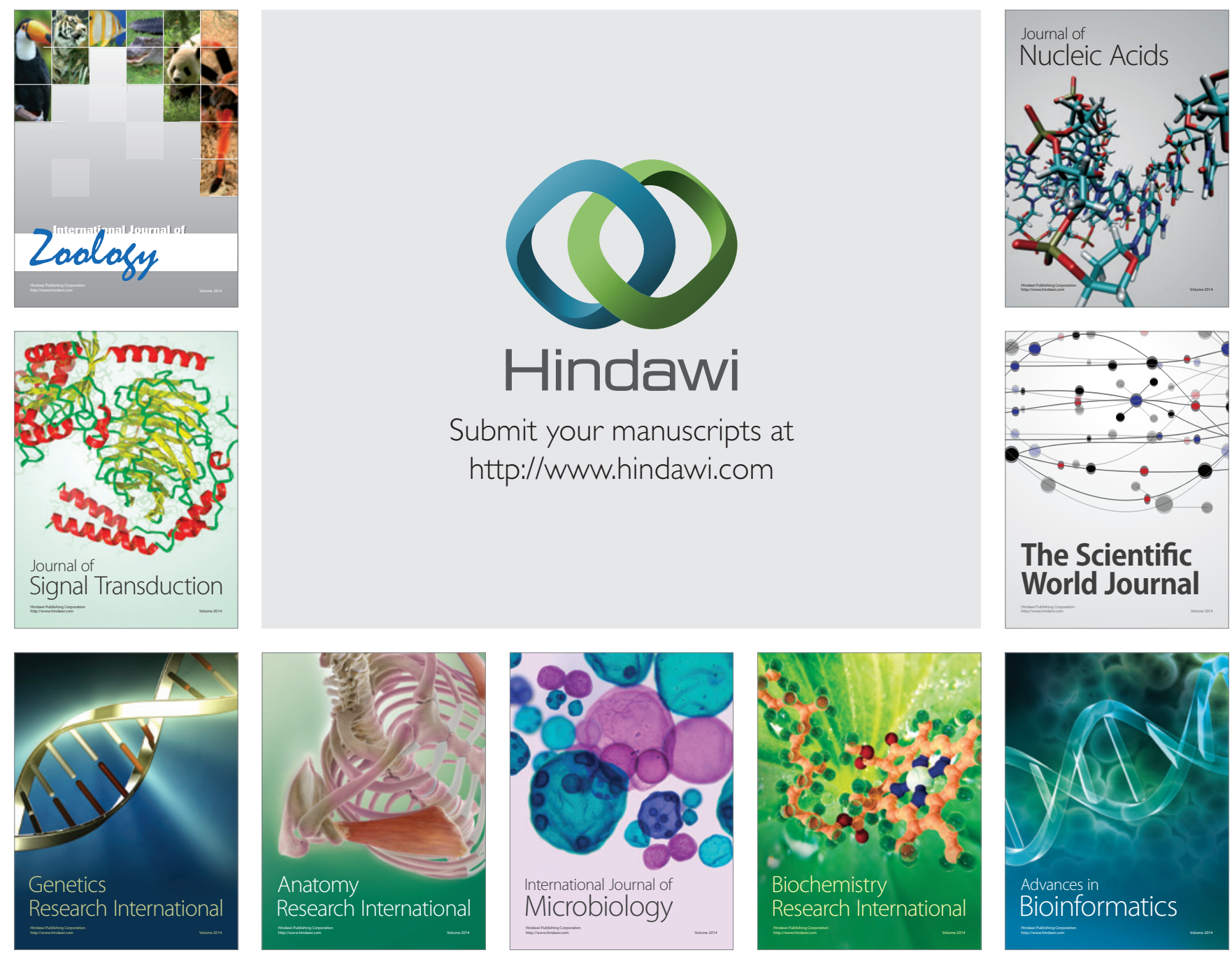

The Scientific World Journal
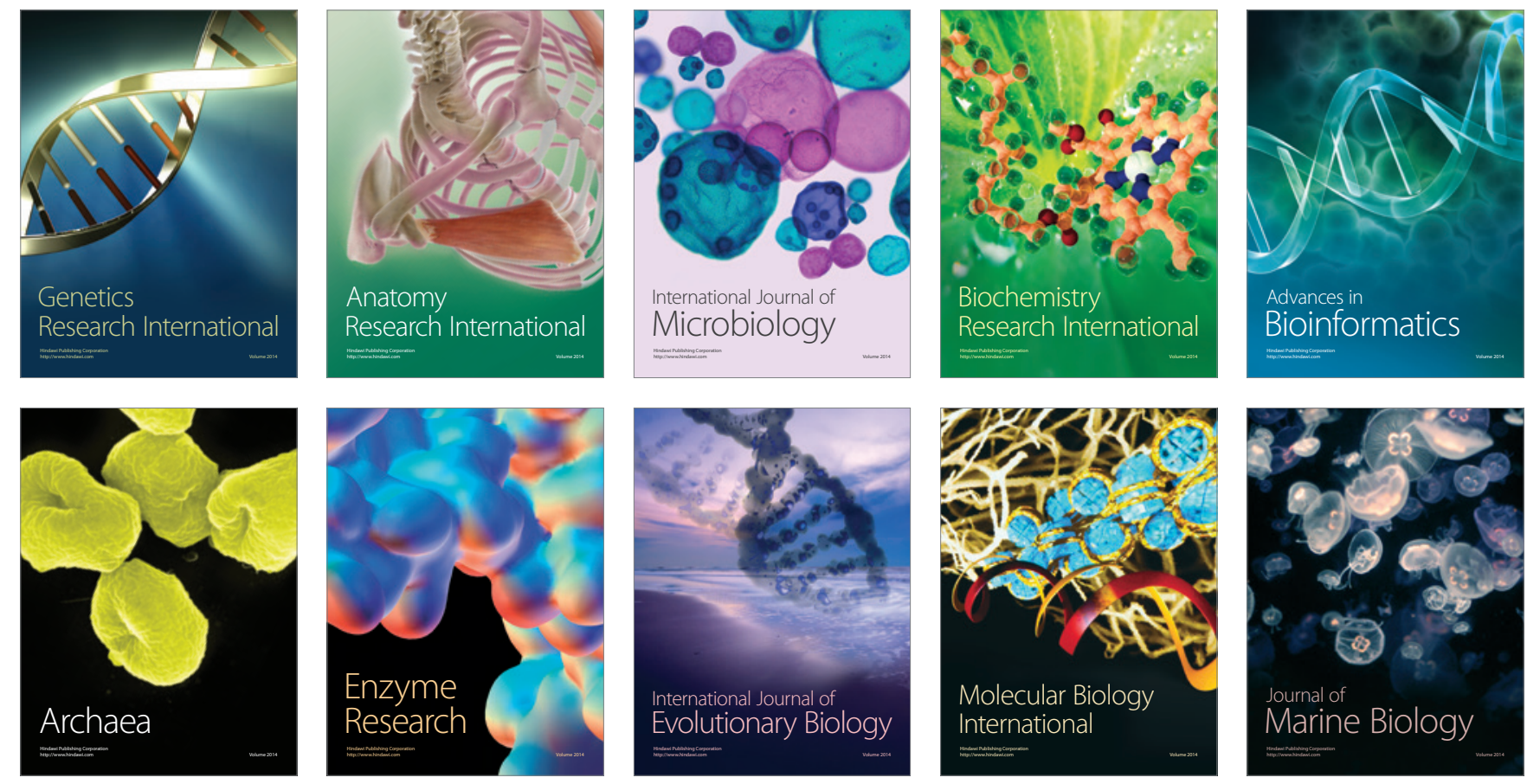